\title{
MANN Y NIETZSCHE: LA ESTÉTICA DE LA ENFERMEDAD
}

\section{MANN AND NIETZSCHE: THE AESTHETICS OF ILLNESS}

\section{ABSTRACT}

The paper proposes a reading of the illness as aesthetic means in the frame of literary practice. The exposition will start from an analysis of Death in Venice, by Thomas Mann, work where the speech on the illness and the aesthetics of the novel are constructed mutually. Later I propose a hypothesis about the illness in Friedrich Nietzsche's life and creation, both in aesthetical and ethical meanings. Finally, as a compendium, I will conclude with a comment on the experience of illness of Hans Castorp, the central character of The magic Mountain, by Thomas Mann.

Key words: Illness, Aesthetics, Beauty, Morality, Madness

\section{RESUMEN}

El artículo propone una lectura de la enfermedad como recurso estético en el marco de la práctica literaria. La exposición partirá de un análisis de La Muerte en Venecia, de Thomas Mann, obra en donde el discurso sobre la enfermedad y la estética de la novela se construyen mutuamente. A continuación se propondrá una hipótesis sobre como la enfermedad se torna, en la obra y la vida de Friedrich Nietzsche, en un recurso estético e, incluso, ético. 
Finalmente, a manera de compendio, se concluirá con un comentario sobre la experiencia de la enfermedad, estética y de vida, de Hans Castorp, el protagonista de La montaña mágica, de Thomas Mann.

Palabras clave: Enfermedad, Estética, Belleza, Moralidad, Locura.

Fecha de recepción: 6 de mayo de 2019.

Fecha de aceptación: 21 de mayo de 2019.

Cómo citar: Panico, Francesco, «Mann y Nietzsche: La estética de la enfermedad», en Actio

Nova: Revista de Teoría de la Literatura y Literatura Comparada, 3 (2019): 56-77.

DOI: https://doi.org/10.15366/actionova2019.3.003 


\section{INTRODUCCIÓN}

El Decamerón de Giovanni Boccaccio se abre con una historia que, como siempre sucede en la novela antigua, constituye el péndulo del que se mecen muchas otras, posiblemente infinitas: la llegada de la peste a Florencia obliga a un grupo de jovencitos, siete mujeres y tres hombres, a refugiarse en las colinas contiguas a la ciudad. Al principio, dudan acerca de cómo pasar el tiempo y, por el hecho de que estamos en una época que aún no conoce las redes sociales ni la esclavitud del celular, resuelven que la mejor manera de hacerlo es contarse historias.

En esta gran novela, precursora de toda la tradición posterior, la enfermedad es una astucia narrativa y, en paralelo, un artificio formal. Eso quiere decir que la enfermedad, en el Decamerón, en cuanto expresión de una serie de instancias arraigadas en la cultura, adquiere una particular relevancia estética (Grmek y Gourevitch, 2000). El conjunto del que se descuelgan los cuentos del Decamerón guarda una doble cara: la de la peste, es decir, el caos aniquilador, y la del orden ideal recreado por los jóvenes narradores, cuyo fundamento es el amor. Este doble aspecto tiene evidentes repercusiones sobre la estética de la novela: por un lado tenemos a la enfermedad como alegoría del caos, y por el otro a la literatura como paladín del orden y el sentido. Las historias (todas) son, al fin y al cabo, un intento de enmendar ese caos y transformarlo en un orden (Reyes, 2012). Así que la enfermedad, en la obra de Boccaccio, es una poderosa palanca para la búsqueda de una peculiar forma de belleza (Surdich, 2008).

Pero si de los tiempos antiguos nos desplazamos hacia los nuestros descubrimos que, pese a que cambian las estrategias de adaptación de la literatura a la cultura (y viceversa), este principio formal se conserva. Por ejemplo, con la implantación en Europa de la sociedad de masa y la individualización del sujeto a mediados del siglo XIX, la enfermedad se impone como una excelente metáfora de la civilización moderna (Canetti, 2013: 81 ). En El corazón de las tinieblas, de Joseph Conrad $\left(2011^{2}\right)$, es la misma geografía que delata desde el inicio, cuando una manada de fortuitos marineros romanos surca el Támesis a la altura de lo que será después la ciudad de Londres, el clima patológico que recorre toda la novela. En La caída de Albert Camus $\left(2012^{3}\right)$ vemos a un hombre que se confiesa ante un tú genérico, con la

\footnotetext{
1 Primera edición: 1960.

2 Primera edición: 1902.

3 Primera edición: 1956
} 
esperanza, quizá, de ser perdonado. ¿Por quién? Por el lector (el tú genérico, precisamente), quien se sabe igualmente hipócrita que el narrador en la tranquila soledad de su lectura. Ambos comparten la enfermedad existencial del hombre, en general, y del hombre moderno, en particular, condenado a convivir con su mala consciencia. En El Horla de Guy de Maupassant $\left(2008^{4}\right)$ la enfermedad es un mal que aletea, de manera siniestra, sobre la vida del protagonista: el narrador, para sorprender en el acto a esta presencia que lo domina, finge quedarse distraído durante los ratos en que escribe. En La consciencia de Zeno de Italo Svevo $\left(2009^{5}\right)$ el narrador, invitado por su sicoanalista (a quien odia profundamente) a referir la historia de su enfermedad, termina escribiendo una autobiografía. El resultado de ello es que, de las cenizas de su fragmentado yo psicológico, nace una lúcida, no menos que cómica, identidad estética, como si el acto mismo de narrar fuera un modo de proporcionar unidad a lo informe, lo mismo que les sucede a los diez jóvenes narradores de Boccaccio.

En este artículo intentaré profundizar el asunto de la enfermedad como forma partiendo de otra novela ejemplar del siglo XX: La muerte en Venecia ${ }^{6}$, de Thomas Mann. A ella estará dedicada la primera parte del escrito. A continuación, trataré la obra y la persona de Friedrich Nietzsche para observar como la enfermedad pudo incluso servir de modelo a la estética de una vida. Finalmente, a modo de compendio y conclusión, presentaré una reflexión sobre La montaña mágica de Thomas Mann, cuyo protagonista, Hans Castorp, se acerca a los fundamentos espirituales de su existencia gracias a una "mancha húmeda" que los doctores detectan en sus pulmones.

\section{El EXTRAÑAmiento}

El protagonista de La muerte en Venecia de Thomas Mann, Aschenbach, es un intelectual reconocido por sus trabajos sobre Federico de Prusia, por su novela Los Mayas, por el cuento largo Un miserable y por el apasionado ensayo Espíritu y Arte. También es un modelo de conducta para la sociedad burguesa de su tiempo: de excelentes modales, acomedido, sensato, sabio; en una palabra: intachable. Su espíritu se mantiene a una prudente distancia tanto de lo común como de lo excéntrico. Lo mismo pasa con su ingenio, que sabe

\footnotetext{
${ }^{4}$ Primera edición: 1887.

${ }^{5}$ Primera edición: 1923

${ }^{6}$ Primera edición: 1912

7 Primera edición: 1924
} 
cómo ganarse la confianza de las masas, pero también la de un público más refinado y puntilloso. Desde que era joven, el compromiso con su trabajo lo había hecho, sin casi que de ello se diera cuenta, un individuo precozmente docto (una suerte de Leopardi sin joroba), refractario al ocio y a la despreocupada indolencia de la mocedad.

Un día entre los días, decide salir a las calles de Múnich, su ciudad, para distraerse un poco. Se siente muy emocionado por su último trabajo. Le pasa exactamente lo que a cualquier pensador profesional: durante la caminata, su inteligencia y reflexión despiertan, permitiéndole por fin encarar las dudas que lo asechaban mientras aún permanecía sentado sobre de un cómodo sillón en la tranquilidad de su casa. Todavía no ha resuelto el dilema de qué estructura formal es preciso adjudicarle a su nuevo libro para que sus materiales de investigación alcancen un orden bello y coherente. Por ello, su alegría, por cuanto muy presente, corre aún sobre el hilo sutil de la desesperación.

Pese a su deambular distraído, su mirada se posa sobre la figura de un hombre medio harapiento, con toda la pinta de quien no ha tocado el agua desde hace varios días. Lo acompañan los típicos signos de un viajero: una mochila, una larga barba y un bastón de madera en el que el hombre, en actitud contemplativa, recarga su flanco derecho. Esta imagen le produce al escritor una sensación rara, de extrañamiento. ¿Qué es lo que siente? Siente que quisiera ser un poco ese viajero, liberarse del peso de su fama y de su vida en extremo rutinaria, aunque fuese solamente por unas semanas, no más. Sueña con húmedos ambientes tropicales, habitados por tigres en busca de sus presas, monos saltadores, panteras negras como la noche, y mosquitos impertinentes que no dejan de atormentar su blanca piel de animal urbano. La idea de regresar a su casa de campo, donde su anciana criada le cocina la comida de todos los días para que el gran Aschenbach no se distraiga de sus tareas creativas, le provoca sentimientos encontrados, ora de leve fastidio, ora de clara molestia.

Pero, ¿adónde podría fugarse un viejo como él?, alguien que jamás había reparado en este deseo de lejanía. ¿En qué clase de páramo le sería dado retirarse para que el desconcierto que siente deje de angustiarlo? ¿Acaso la suya es una especie de adolescencia retardada? ¿Por qué le está pasando esto precisamente a él, quien jamás ha sido acosado por necesidad alguna de distanciarse de su normalidad? La verdad es que no lo comprende. Por lo tanto resuelve no seguir preguntándose por las causas de aquello y decide concentrarse únicamente en el efecto. Su resolución, por fin, es partir. ¿Adónde? A un lugar lo bastante cercano como para no sentirse fuera de lugar y no tener que a de veras verse cara a cara con 
un tigre. Se le ocurre una idea, un feliz compromiso entre su deseo y su sentido de la mesura: Venecia.

\section{LA BÚSQUEDA DE LA FORMA}

Llega en un Vaporetto. El mar, desde el barco, se le figura como un espejo incoloro sobre el que se refleja un cielo a punto de descargar su húmeda rabia. El aire es pesado, cargado de partículas de agua. El calor, sin embargo, es intenso, aunque, de vez en cuando, un viento ligero que sopla del Lido le provoca uno que otro escalofrío. Su espíritu experimenta sensaciones solo en apariencia discordantes: por un lado, la calma que le infunde la contemplación de un paisaje excepcional, como el de un cuadro de William Turner o de Arturo Bianchi; por el otro, la excitación de quien es consciente de estar al borde de una revelación, como la de un mortal a punto de recibir un oráculo. La suya es una historia que apenas comienza, y este sentimiento de que su desenlace dependa de las decisiones que él tomará, no le resulta para nada alentador. ¿Quién, entre todos estos hombres que se dicen valientes, se atreve en serio a tomar el destino en sus manos? ¿Y quién se cree, sobre todo, de que esto sea posible? ¿Cómo hacerse de esta fuerza que necesitamos para aguantar lo inevitable? Aschenbach, en su fuero interno, sabe que el presagio es, de hecho, una anticipación del futuro, es decir, un porvenir ya escrito, una suerte de sentencia, ante la cual el ingenuo y esperanzado espíritu aún no quiere doblegarse. Él, en realidad, sabe que su voluntad, por sí sola, no puede transformar nada, pero por el solo hecho de que las cosas aún no han sucedido, por esta estúpida razón que le hace esperar que el futuro es una página en blanco aun por escribirse, opta por seguir el camino emprendido. En medio de estos pensamientos, llega por fin al desembarcadero, y de ahí directo al Grand Hotel Des Bains, la residencia que eligiera para su estancia.

La ciudad, desde el primer momento, se encuentra envuelta en un aura surreal. De su aire se desprende un olor fétido, como de cadáver en descomposición: es la peste, que, entre el silencio y la indiferencia, se apodera de sus calles, canales y plazas. La enfermedad, poco a poco, lo empieza a embadurnar todo. Con un movimiento parco pero continuo, se instala en el alma de la población, incluso de la que no se enferma. Más que un evento dramático y accidental, la peste cobra el aspecto de un castigo enviado por una entidad moral superior, ni buena ni mala, pero que pretende enseñarle al hombre, falso y pusilánime, su 
inmenso poderío. El espíritu de Aschenbach se encuentra en la misma condición que Venecia. Una fuerza incontrolada, una forma impertinente y oscura, hace caer el edificio de seguridades burguesas que con tanto ahínco se construyera durante los años más esplendorosos de su fama:

Y la forma, a su vez, ¿no presenta un doble aspecto? ¿No es moral e inmoral a la vez: moral como resultado y expresión del esfuerzo disciplinado, pero amoral, e incluso inmoral, puesto que encierra por naturaleza una indiferencia ética y porque, más aún, aspira esencialmente a humillar lo moral bajo su seño orgulloso y despótico? (Mann, 1982: 18)

La forma toma finalmente su venganza en contra de un hombre que había resuelto, en cierto momento de su vida, no volver a prestarle oído. Ese aliento de putrefacción que relaja su moral y la de la ciudad lagunar entera, es también un aliento de verdad a secas, sin tapujos ni palabras vacías que intenten dulcificar la imagen de una naturaleza indiferente. Esta naturaleza la describe de manera impecable el narrador de La montaña mágica:

Era el silencio puro, el silencio eterno lo que escuchaba Hans Castorp cuando permanecía de pie muy quieto, apoyado en su bastón, con la boca abierta y la cabeza ladeada sobre el hombro; y, dulcemente, la nieve seguía cayendo y cayendo, sin el menor ruido. No, aquel mundo, en su silencio insondable no tenía nada de hospitalario; acogía al visitante a su propia cuenta y riesgo; en realidad no le acogía, sencillamente toleraba su intromisión, su presencia, de una manera un tanto inquietante, como si no respondiera de nada; y lo que de él se desprendía era una atmósfera de amenaza ante lo absoluto, ante lo más elemental, ante algo que no llegaba a ser hostil sino que era la pura imagen de la indiferencia, de una indiferencia mortal. (Mann, 2005: 341)

La forma que le toca en suerte a Aschenbach es, de manera solo en apariencia paradójica, dos cosas a la vez: una enfermedad implacable, la peste, y un rostro angélico, Tadzio, un muchachito ruso de diez años de vacaciones en Venecia. El escritor es atraído por la delicadeza clásica de su aspecto, por la gracia de sus ademanes y expresiones faciales: en suma, por su áurea perfección. Se siente turbado por ello, aunque, como el ser inteligente que es, sabe que no tiene suficiente fuerza para repudiar su sentimiento: lo único que le queda es rendirse ante el coqueteo inmoral de la forma.

El escritor descubre que la ansiedad que experimenta por salirse de su vida rutinaria, hecha, en el fondo, de letras vacías, coincide con un deseo de forma, que se traduce en una suerte de desafío hacia el pasado y el presente: un deseo de cambio, muy semejante (mas no 
igual) al que acomete al Pereira de Tabucchi $\left(2013^{8}\right)$, cuando, en clínica, durante una plática con su médico, se entera de que existe una teoría psicoanalítica llamada "la republica de las almas", en la que se sostiene que habrá un momento en la vida de cada uno de nosotros en donde el anhelo de cambio vencerá al de conservación. Surgirá entonces una nueva personalidad, y la vida tendrá un giro inesperado. De viejo aburrido, Pereira se convierte en un guerrero, en un rebelde sabio y gordo, dispuesto incluso a morir. Algunos podrían opinar que este impulso de vida y de cambio es, en realidad, un deseo de muerte, cimentado en la voluntad de alcanzar a su difunta esposa, con cuya fotografía se entretiene habitualmente al cruzar el umbral de su departamento de la Rua de Saudade. Ahora bien, Pereira, como Aschenbach, no es blanco de un despertar moral, sino de una revelación que sabe no tener el derecho de eludir. En ambos se activa, de repente, una predisposición preexistente, que quizá compartan con todos los humanos. Su alto nivel de autoconsciencia, por ser hombres de letras, los ayuda en darse cuenta de ello mucho antes que cualquier hombre común, aunque este despertar, en ambos personajes, no es garantía de una vida mejor, sino de un florecimiento que conduce irremediablemente a la muerte. Por lo demás, todo florecer es esto: una explosión súbita de belleza que se repliega bruscamente sobre sí misma. ¿Y no se podría decir lo mismo de la vida? ¿No es el vivir, como decía Dante, "un correre a la morte”? (Alighieri, 1988: $\left.865^{\circ}\right)$. ¿Nacer, no es un poco como iniciar a morir? ¿Y la carne, más que la materia de la vida, no es también la primera manifestación de la muerte? Ahora bien, este pacto entre la vida y la muerte que se establece dentro del mundo orgánico, no se expresa, según lo que sugiere La muerte en Venecia, por vía moral o ética, sino estética. La belleza es, en pocas palabras, la forma en la que el mundo se representa a sí mismo, y nosotros los humanos contamos con el privilegio de recrearnos en ella por conducto de la vista. Aquí reside nuestra dicha y, a la vez, nuestro tormento.

En un texto muy sugerente, el biólogo Jacques Monod (2007: 137), al hablar de la evolución, afirma que en la naturaleza existe un estrecho emparejamiento de las adaptaciones anatómicas con las performances específicas. Si vemos esta tesis a la luz de la reflexión anterior, nuestro aparato visual habría evolucionado paralelamente a nuestro "deseo" de ver, como si la voluntad de llegar a ser algo fuera el motor que empuja hacia cierto resultado (Menninghaus, 2015: 89). Se puede decir, entonces, que la aspiración de lo humano era,

\footnotetext{
8 Primera edición: 1994

${ }^{9}$ Primera edición en prensa: 1472. Sin embargo la obra fue escrita durante las primeras dos décadas del siglo XIV.
} 
mucho antes de que este humano existiera en carne y huesos, llegar a gozar de las formas del mundo, y que sus ojos, de manera especial, son un instrumento de contemplación de la belleza (Dutton, 2014: 152).

Alcanzado por la belleza, Aschenbach ya no siente vergüenza. Su máscara moral ha caído. Fedón ha sido convencido por Sócrates, su maestro, de que la belleza lleva al poeta a la perdición, la embriaguez y el deseo. Es más: la maestría de su estilo es falsa, fingida y demente. Su gloria y estimación son pura farsa, y es improbable y hasta ridícula la estimación en la que el pueblo lo tiene:

El contemplador estaba allí, sentado en el mismo sitio donde por primera vez la mirada de aquellos ojos de ensueño se había cruzado con la suya. Su cabeza, apoyada en el respaldo de la silla, seguía ansiosamente los movimientos del caminante. En un instante dado se levantó para encontrar la mirada, pero cayó de bruces, de modo que sus ojos tenían que mirar de abajo arriba, mientras su rostro tomaba la expresión cansada, dulcemente desfallecida, de un adormecimiento profundo. Sin embargo, le parecía que, desde lejos, el pálido y amable mancebo le sonreía y le saludaba. Pasaron unos minutos antes de que acudieran en su auxilio; había caído a un lado de su silla. Le llevaron a su habitación, y aquel mismo día, el mundo, respetuosamente estremecido, recibió la noticia de su muerte. (Mann, 1982: 97)

La muerte de Aschembach, en la escena final de la novela, representa la solución última (y el único desenlace posible) al manifestarse de su nueva personalidad, dominada por un sentido estético moralmente repudiado por la sociedad y, aunque solo en un principio, por él mismo. La belleza es, en última instancia, la culminación de su magnífica (y mortífera) transformación espiritual.

\section{LA ENFERMEDAD COMO FORMA}

En La muerte en Venecia, la enfermedad no sólo es un contenido, un tema, un escenario, un personaje, sino, como se ha visto, es una forma estética, y como tal puede y debe ser leída. Pese a que el narrador le siembra previamente algunos indicios, a Aschenbach lo coge de repente un instinto clásico de belleza provocado por Tadzio. Este instinto, para un hombre como él, debido a la edad y al sexo del joven, es de naturaleza inmoral. La enfermedad, tanto la de la ciudad como la suya, lo ha introducido a una experiencia estética poderosa y peligrosa, cual jamás había experimentado, ni en su mejor literatura. ¿Quién es 
Aschenbach, ahora? ¿El degenerado que se masturba pensando en los lacios cabellos rubios de este niñito impertinente?, ¿o el esteta rendido ante la impudicia de la belleza, sin importar bajo qué forma ella se presente? Conforme la lectura avanza, uno se identifica, un poco se escandaliza, luego se ríe, pues parece que lo sano se junta con lo podrido, los ángeles con los diablos, la carne con el pescado, los perros con los gatos, etcétera. La idea de que el mal, en la que caben también nuestras más hondas perversiones, pueda interpretarse como una manifestación de la belleza, nos resulta inaudito, desagradable y escandaloso.

De nuevo es el narrador de La montaña mágica quien nos arroja una perspectiva sugestiva sobre el tema:

La anatomía patológica, uno de cuyos volúmenes sostenía inclinado hacia la luz roja de la lámpara, le informaba [a Hans Castorp, el protagonista de la novela], por medio de un texto sembrado de ilustraciones, sobre el carácter de los grupos parasitarios de células y tumores infecciosos. Eran formas de tejidos -particularmente lujuriantes- provocadas por la irrupción de células extranjeras en un organismo acogedor y que, de algún modo -tal vez sea preciso decir de un modo depravado-, ofrecía a su crecimiento condiciones favorables. [...] La apariencia exterior de esta corrupción era la de una excrecencia de tejidos, el tumor patológico que constituía la reacción de las células contra los bacilos establecidos entre ellas. Nudos espesos se producían, compuestos de células aparentemente viscosas, entre las cuales y en las cuales se instalaban las bacterias, y algunas de estas células eran extraordinariamente ricas en protoplasmas, inmensas y cubiertas de una multitud de nudos. Pero esta efervescencia conducía a una rápida ruina, pues de inmediato los nudos de estas células monstruosas comenzaban a descomponerse y su protoplasma a lubricarse, nuevas zonas vecinas de tejidos eran invadidas por aquella afluencia extranjera, fenómenos de inflamación se iban difundiendo y atacaban los vasos vecinos, los glóbulos blancos se aproximaban atraídos por el desastre, la muerte por coagulación progresaba y, sin embargo, los venenos solubles de las bacterias habían embriagado, desde hace mucho tiempo, los centros nerviosos; el organismo alcanzaba una temperatura elevada y con el pecho tempestuoso marchaba tambaleándose hacia la disolución. (Mann, 2005: 238)

El cáncer descrito por Mann es sí una enfermedad monstruosa, pero no deja de ser una manifestación de la vida, es decir, mecánicamente hablando, un dispositivo de degeneración de la materia orgánica, cuya descripción puede ser incluso bella. La vida misma es una suerte de cáncer, producto de una alteración química que, en un momento dado, sin explicación alguna ni causa directa que la provocara, hace acto de presencia en el planeta. Sigamos escuchando al extraño narrador de La montaña mágica:

¿Qué era, pues, la vida? Era calor, calor producido por un fenómeno sin sustancia propia que conservaba la forma: era una fiebre de la materia que 
acompañaba el proceso de la descomposición y la recomposición incesante de moléculas de albúmina de una estructura infinitamente complicada e ingeniosa. Era el ser de lo que en realidad no puede ser, de lo que oscila en un dulce y doloroso vaivén sobre el límite de la existencia. No era ni siquiera materia y tampoco espíritu. Era algo entre los dos, un fenómeno llevado por la materia, semejante a la llama. Pero aunque no sacase nada de la materia, era sensual hasta la voluptuosidad y la repugnancia, el impudor de la naturaleza convertida en sensible a ella misma, era la forma impúdica del ser. Era la vegetación, el desarrollo y la proliferación de algo hinchado, compuesto de agua, albúmina, sal y grasas, que se llama «carne» y que se convierte en forma, imagen y belleza, pero que es el principio de la sensualidad y el deseo. Pues esta forma, esta belleza no es llevada por el espíritu, como en las obras de la poesía y la música, sino por la sustancia que despierta, de una manera desconocida, a la voluptuosidad, por la misma materia orgánica que vive descomponiéndose, por la carne perfumada. (Mann, 2005: 251)

El cáncer es también esta carne hinchada, un fenómeno aún más voluptuoso, impúdico y sensual que el del normal proliferar de las células sanas en nuestros huesos y tejidos. Parece que cada cosa en el mundo, animada o inanimada que sea, proceda de una sustancia común que, si agitada por profunda pasión, puede convertirse en lo que sea. En el seno de la forma, vida y muerte ya no son categorías morales, sino manifestación de un devenir que se repite incesantemente bajo diferentes aspectos. El humano de hoy, ni el de los tiempos de Mann (ni de ningún otro, me imagino), esto no lo puede aceptar, pues su mundo es y debe ser un mundo moral, donde se pueda distinguir, con cierto grado de seguridad, lo que es bueno de lo que es malo. Pero el gran Aschenbach no podía terminar su vida sin haber hecho la experiencia de una belleza que lo llevara más allá del humano (demasiado humano) mundo moral al que siempre se había adherido. La enfermedad, en la novela, hace alarde de belleza, por eso resulta desconcertante.

Aquí es donde nos conectamos con Nietzsche, uno de los más enjundiosos enemigos de la moral y la ética, ambas juzgadas incapaces de ofrecer un molde adecuado a las pasiones humanas. El mundo sólo lo podemos conocer por vía estética, nos dice Nietzsche, porque así es cómo llegamos a apropiarnos de sus formas sin tenerlas que juzgar, libre y honestamente. Se comprende, entonces, como la enfermedad no haya significado para él un impedimento, sino al contrario un factor de enaltecimiento, que lo llevó a convertirse en lo que era. Extraña frase esta de "llegar a ser lo que se es". Bajtín, el conocido crítico ruso, la cita en su análisis de la obra de Dostoievski: "En Dostoievski el hombre no sólo se proyecta hacia el exterior, sino que por primera vez llega a ser lo que es.” (Bajtín, 2005: 455). Este lema, en sí, no significa absolutamente nada, pero en el contexto de la poética de Dostoievski, de carácter exquisitamente dialógico, el personaje solo puede ser tal en cuanto 
voz que se expresa al interior de un concierto de voces que arrojan cada una un punto de vista diferente sobre el material narrado. Bajtín nos enseña que la verdad, en el arte (y quizás en la vida), jamás es una verdad moral, sino siempre y solo estética. La verdad concierne a la forma, no al contenido (Bateson y Bateson, 2013; Burger, 1994). Por ello podemos hallarla incluso en los lugares que, en apariencia, juzgamos menos plausibles. De ahí que él se interesara tanto por el carnaval en su interpretación de la historia de la literatura, en especial de la novela. En el carnaval, todo toma el aspecto de otra cosa. Es inexacto decir que en él las reglas éticas y morales son revertidas, sino son sencillamente suspendidas (Bajtín, 2003). El disfraz indica incertidumbre, duda, pero sobre todo resalta la fundamental inautenticidad de la identidad, bajo la cual tan a menudo los hombres nos resguardamos por tener miedo de llegar a ser lo que somos. La farsa y la burla lo dominan todo. El carnaval se toma la ligereza muy en serio y la seriedad muy a la ligera. La moral, por supuesto, es parte del juego, no su fundamento, y el hombre, posiblemente, llega a ser lo que es precisamente donde menos lo esperaba.

La enfermedad y el carnaval: extraño binomio, pero que en Nietzsche se saludan con un fuerte apretón de manos, cuyo desenlace último es la locura, quizás el mayor logro artístico del gran autor. Es de estos sus últimos años de enajenación donde quiero emprender mi lectura de la estética nietzscheana.

\section{NIETZSCHE: LA ENFERMEDAD COMO MOTOR DE LA VIDA}

Parece insólito iniciar mi argumento desde los once años en que Nietzsche permaneció en la más honda oscuridad espiritual, pero a veces las interpretaciones toman un giro inesperado, sin que el intérprete pueda hacer nada al respecto. Pues bien, uno de los lemas favoritos de Nietzsche es que el hombre, para llegar a ser lo que es, debe salirse de sí mismo, superar las limitaciones de su propia consciencia, la cual le da la ilusión de una identidad impermutable. La consciencia es su mayor enemiga:

La conciencia es la última y más tardía evolución de la vida orgánica y, por consiguiente, lo más inacabado y frágil que hay en ella. De la vida consciente proceden innumerables errores que hacen que un animal o un ser humano perezcan antes de lo que hubiera sido necesario "a pesar del destino", como dijo Homero. (Nietzsche, 2002: 47) 
Para Nietzsche salirse de sí mismo significó cortar cualquier adherencia con esto que llamamos conciencia. ¿Qué mejor solución para ello que la de volverse completamente loco? Sigamos entonces esta huella, sin la pretensión, desde luego, de convertirla en una sentencia. Es obvio que Nietzsche de ninguna manera planeó su locura. Sin embargo, podía (como lo hiciera el Adrián Leverkühn en el Doktor Faustus ${ }^{10}$ de Thomas Mann) decidir irse con unas prostitutas para que éstas le obsequiaran el don más preciado: la sífilis (Mann, 2010). El episodio de Leipzig es muy famoso. Nietzsche tenía poco más de veinte años en ese entonces. Ciertamente, no programó tan exactamente su porvenir (no podía tener conciencia de sus opiniones futuras), sino simple y llanamente cayó víctima, como Ulises, de la seducción de aquellas bellísimas mujeres, tapadas apenas con unos cuantos velos. El de la sífilis como un regalo del Hado, hubo de ser un pensamiento que al gran filósofo se le ocurrió mucho después. Pero si es cierto esto de que el deseo, incitado por el cuerpo, siempre se adelanta a la consciencia, entonces podría suponerse que Nietzsche "quiso", ante litteram, adquirir la enfermedad:

El cuerpo es una gran razón, una pluralidad con un único sentido, una paz y una guerra, un rebaño y su pastor. Instrumento de tu cuerpo es también tu pequeña razón, hermano mío, a la que llamas "espíritu”, un pequeño instrumento y un pequeño juguete de tu gran razón. Hay más razón en tu cuerpo que en tu más alta sabiduría. (Nietzsche, 2008: 64).

Al parecer, los hombres "pensamos" también con el cuerpo. Quien se figura que la raza humana sea capaz de librarse de la materia y así alcanzar las cumbres más elevadas de la sabiduría y la razón, es un necio y un crédulo (Nietzsche, 2005: 42). La enfermedad, que es parte del organismo y no un simple accidente, obliga a buscar un nuevo equilibrio, un nuevo porqué, una nueva explicación, más allá de las vaguedades superficiales de mucha filosofía especulativa (Bacarlett, 2006: 81). Ella es un medio necesario para salirse de sí mismo, más no suficiente. Para lograrlo hay que torcerse hasta lo irremediable y no contar siquiera con la posibilidad de revertir el camino. La muerte, por supuesto, sería demasiado, pues acabaría con cualquier aliento de transformación; sería, de hecho, una mutación exageradamente radical. Por ello la locura, o sea una liviandad que se hace mofa de la consciencia y se abre camino con la seguridad de un payaso, como el mismo Nietzsche le comparte a su amigo

10 Primera edición: 1947. 
Köselitz en una carta fechada 26 de noviembre 1888, pocos meses antes de que sucediera lo inevitable:

Me empeño tan a menudo en bufonadas conmigo mismo y tengo tantos ademanes privados de payaso, que me sucede hacer muecas durante horas mientras ando por la calle, no sabría encontrar otro término. Hace unos días, pensé presentar, en un paso decisivo de Ecce homo, Malwida como Kundry, que ríe -------. A lo largo de cuatro días no logré brindar a mi rostro ninguna expresión de aplomo. En este estado, mi pregunto, ¿estará uno listo para ser el redentor del mundo? (Janz, 1982: 21)

La risa desempeña aquí el papel de un oráculo que, ni tan herméticamente, le enseña a Nietzsche el camino que pronto emprenderá su espíritu. El carnaval está por llegar y la consciencia por desaparecer, con el paso de quien carga, como diría Calvino (2016: 27), un peso sumamente ligero. Las palabras del amigo Overbeck, llegado de prisa a Turín tras su primera crisis, no necesitan de comentario alguno acerca del estado del filósofo:

Había entrado en el mundo de sus alucinaciones, del que jamás volvió a salir hasta que yo estuve ahí, manteniéndose sin embargo lucido hacia mí y los demás conocidos, pero completamente eclipsado respecto a su persona. Valga el ejemplo de cuando, sentado al pianoforte, donde cantaba a pleno pulmón en poder del frenesí y exaltándose cada vez más, desbordó en un arrebato de aquel mundo de ideas en el que vivía en los últimos tiempos. Pronunciaba frases terribles en un tono sutil, acompañándolas con puntuaciones al pianoforte, para luego caer de nuevo en convulsiones y furores. Al poco tiempo, volvía a calmarse. En general, sus discursos vertían sobre la misión que él se atribuye: la de ser el payaso de la nueva eternidad (Janz, 1982: 35)

En sus primeros tiempos de demencia, volvemos a encontrar a un Nietzsche más sosegado, dominado por una serenidad infantil. Sus amigos lo dan de alta en una clínica de Basilea, en donde se quedará por catorce meses. Durante este tiempo, quien cuida de él sin dejarlo un solo instante es su madre, mujer devota, arraigada en la fe y de simples creencias. Su sacrificio es ejemplar, y adquiere la talla de una misión casi imposible en la que el amor incondicionado por su hijo y una inocente compasión cristiana se mezclan en un todo único.

En este periodo Nietzsche es el hombre que describe su madre durante una de sus acostumbradas visitas a los balnearios cercanos a la clínica:

Dos días antes de nuestra partida fuimos como de costumbre a tomar un baño de agua salina. [...] Procuro obligarlo a que se ponga ropa adecuada, pero él no quiere, e insiste en querer salir con su bata toda gastada. Luego toma su sombrero y se va. No sirve de nada rezarle que no lo haga. Yo tenía que llevar 
todo lo necesario y él se iba al balneario. Imprudentemente, regreso para tomar algunas cosas que se me habían olvidado, bajo al balneario, pero él no estaba. Lo busco al Paradies, donde comemos seguido, al Stern, con el barbero: nada, no le encuentro en ningún lado. Una angustia mortal. Finalmente, resuelvo ir con la policía, cuando, acalorada y bañada en sudor, tras haber doblado la esquina de la Kollegienstrasse, lo veo bajar en compañía de un policía, hablando de manera cordial. Me dijeron que quiso meterse a una alberca cerca del baño de los varones, y que luego había andado desnudo por un buen rato (Janz, 1982: 112).

El incidente provocó un pequeño escándalo, hecho que convenció a su familia a contratar a un enfermero y acelerar los preparativos para su salida a Naumburg, su ciudad natal. Nietzsche aparenta ser ahora el payaso al que hiciera otrora alusión en su estancia de Turín. Un hombre sin duda ridículo, cuyo sentido del pudor antes de su obscurecimiento espiritual le hubiera impedido conducirse de esa forma. El hombre cuerdo se habría imaginado probablemente otro desenlace, aunque en su fuero interno el niño implacable e desconsiderado siempre había deseado actuar de ese modo. Es como si en sus últimos tiempos, el filósofo, presionado por el enfant terrible que le disputaba el control de su alma, estallara en mil pedazos y se rindiera ante las consecuencias extremas de sus ideas sobre la vida y la estética, la muerte y la enfermedad. La forma, de manera furtiva, como si de lo alto o desde adentro se le impusiera sin posibilidad alguna de resistírsele, había tomado finalmente las riendas, haciéndole perder el control sobre sus pensamientos y acciones. La sífilis, a condición de que la consideremos el principal motivo de sus últimos años de demencia, fue el juguete preferido de ese niño que se rebelaba a la consciencia en respuesta al adulto que pretendía controlar, a través de una exasperada cuanto endeble vigilancia racional, los impulsos más excéntricos de su compleja personalidad.

Para ejemplificar de manera precisa estas últimas reflexiones debemos escuchar las palabras de los que hacían visita al filósofo durante el periodo en el que fungió, irónicamente, como pieza principal de su propio museo, en Weimar, la ciudad de Goethe, donde su hermana Elisabeth, preocupada por conservar el buen nombre de la familia, lo había encerrado cual animal de circo:

De estas pupilas profundamente melancólicas, que parecían ver lejos y sin embargo se volcaban hacia el interior, emanaba una poderosa energía, un magnético fluido espiritual, ante el cual ninguna naturaleza sensible podía quedar indiferente. Envuelto en ropa blanca, [Nietzsche] descansaba sobre un sillón, hacia el que me acerqué con temor [...]. Sus ojos se posaron sobre de mí con expresión indagadora y pensativa, y luego, sacudiendo la imponente cabeza, dirigió, con la mirada, una muda pregunta a su hermana, quien, acto seguido, le susurró palabras cariñosas. Mientras, de las manos del maestro Peter Gast, se 
desprendieron sonidos estupendos, poderosas cascadas de notas, que se adueñaron del enfermo como por arte de magia, haciendo que vibrara todo su organismo. Una beata éxtasis se le pintó en la cara y todo su cuerpo cayó presa de una indecible emoción. Y entonces sus manos, rompiendo las cadenas del torpor, se movieron una hacia otra en el gesto del aplauso. No se cansaba de manifestar de esa manera su contento. Al cabo de un rato, las cuerdas enmudecieron, pero él, viendo hacia su hermana en búsqueda de anuencia, seguía agitándose por la delicia, en una verdadera eclosión de entusiasmo punteada por los aplausos y las expresiones de su rostro (Janz, 1982: 173).

Esta entusiastica e involuntariamente cómica descripción del enfermo Nietzsche, cuya firma es de la baronesa von Ungern-Sternberg, una vieja conocida suya, es el marco ideal para encuadrar la irónica suerte que al amor fati le dispensó al filósofo, obligado ahora a padecer una condición existencial que no le dejaba escapatoria. Fue este el precio de la pérdida total de su consciencia y fue también este el premio que recibió tras haber perseguido por tanto tiempo su deseo de convertirse en un payaso.

Todo el mundo sabe que Nietzsche, desde muy pronto, había desacreditado su primera obra, El nacimiento de la tragedia, por juzgarla demasiado académica y fríamente analítica. En ella, se reprocha, la forma está ausente. Este asunto de lo dionisiaco y lo apolíneo, que es el tema más conocido del libro, por cuanto genial había sido su exegesis, respondía a una inquietud excesivamente filológica. Con el tiempo nuestro autor descubrió que lo dionisiaco y lo apolíneo no podían ser objeto de una interpretación "técnica" de la historia de la cultura, sino debían plasmarse en la forma de una obra y, posiblemente, de una vida: de su propia vida. Para ello, sin embargo, se precisaba de un horizonte estético más que filosófico o científico. La vida, simplificando verbalmente el concepto, debía seguir el mismo orden formal que el de una obra de arte. Esta fue la idea que hizo nacer a Zaratustra, el avatar de Nietzsche en las páginas de su famoso libro, como el personaje Dante Alighieri, el explorador medieval del edificio divino, lo fue del autor Dante Alighieri. Hay una inquietud estética de fondo que acomuna estas experiencias tan distantes en el tiempo. Nietzsche, como lo hiciera también Dante en relación con el mundo clásico, quería volver a pisar el camino de sus maestros griegos y el de todos los sapientes hasta por lo menos el siglo XVIII: el conocimiento necesita de la forma, es decir de un principio estético ordenador, más que de la seca y problemática neutralidad del método (Dewey, 1934: 239). En pocas palabras, el conocimiento no puede renunciar a la belleza (Carr, 1999: 199). Alguien podría justamente objetar, desde un punto de vista moral, que volverse loco no tiene nada que ver con la belleza, pero habría que considerar esta provocación como un gran símbolo de la trayectoria de 
Nietzsche y, a la vez, como un irónico epílogo de su amor fati. Si el Nietzsche cuerdo hubiese visto desde afuera al Nietzsche loco estoy seguro de que se habría echado una sonora carcajada. El estilo, por fin, le había ganado la disputa a esa gruñona de la consciencia, amargada y siempre insatisfecha.

Aunque de manera mucho menos radical, el estilo fue un método de conocimiento hasta por el mismo inventor del método científico: Galileo.

Si el discurrir acerca de un problema difícil fuera como cargar pesas, donde muchos caballos llevarán más sacos de trigo que uno solo, yo estaría de acuerdo que los muchos discursos harían más que uno; pero el discurrir es como el correr, y no como el cargar, y un caballo bérbero en solitario correrá más que cien caballos frisios (Galilei, 2008: 18).

Esta cita de Galileo no sirve, obviamente, para ofrecer una justificación influyente a mi argumento, sino para seguir sugiriendo un camino de interpretación un tanto excéntrico, que puede sin embargo echar lumbre sobre algunos aspectos de la estética literaria, y hasta de la filosofía.

Sin duda la solución de Nietzsche fue algo extrema, pues acudió a la locura para silenciar su conciencia para siempre: Este fue el gesto estético supremo de un ser trágicamente dionisiaco.

\section{CONCLUSIÓN: HANS CASTORP Y LA PEDAGOGÍA DE LA ENFERMEDAD}

Varios hilos se soltaron a lo largo de este texto. Mi pregunta es: ¿cuál de ellos debo ahora jalar para encontrar entre mis manos la conclusión? Se me figura que el de la enfermedad como formación espiritual. ¿Por qué? Porque me parece el más atinado para servir como trait d'union entre los dos argumentos mayores de este ensayo, a saber: La enfermedad como estética literaria, cuyo soporte fue La muerte en Venecia, y la enfermedad como estética de la vida, ejemplificado por la locura que le tocó en suerte a Nietzsche durante sus últimos años de vida.

El personaje de este último tema es Hans Castorp, protagonista de la ya citada novela de Thomas Mann, La montaña mágica. Este joven hamburgués (lo de burgués está implícito en el gentilicio), durante una visita a su primo que está curándose en un sanatorio de montaña (en la más que famosa Davos, en Suiza), descubre un mundo de conocimiento 
exactamente donde, en teoría, por la lejanía y lo aislado del lugar, no debiera haberlo encontrado. Las cumbres alpinas, en su fría inmovilidad, representan para Hans el centro de la telaraña del universo, de donde y hacia donde corren todos los hilos de lo que se puede saber y de lo que permanece, al contrario, irremediablemente oculto. Este escenario me hace pensar, curiosamente, en Sils-Maria, en donde Nietzsche, antes de que se decidiera por Turín, había vivido gran parte de su existencia de pseudo-anacoreta. Cierro aquí, sin embargo, un comentario que, de seguirlo, me llevaría demasiado lejos.

Decía que Hans, a lo largo de al menos ocho años de permanencia en el Bergoff (el nombre del sanatorio), aprende de todo, en especial, a vivir. ¿Por qué se queda? Por un motivo banal: los doctores le encuentran una "mancha húmeda" en el pulmón. Ésta aparenta ser una especie de entidad mitológica, una irónica versión de las armas mágicas que se les conceden a los héroes de los poemas de caballería para que lleven a cabo sus hazañas. Lo que para Roldán es su Durandarte, para Hans es su mancha húmeda.

En otro nivel, el de la arquitectura de la novela, la mancha húmeda es un artificio narrativo de mucha importancia, puesto que es por ella que el protagonista logra profundizar en ciertos temas que serán luego capitales en cualquier campo del saber a lo largo del siglo XX. Su problema pulmonar es la excusa con la que el mismo Hans justifica, ante sus ojos y los de sus parientes que lo esperan en el "valle", su prolongada estancia en el aparente inmovilismo de la cordillera alpina.

La enfermedad se torna para él en una verdadera pedagogía de la existencia, alternativa a la que le enseñaran en la industriosa y frenética Hamburgo: una pedagogía de la lentitud, del encuentro pausado y bizarro con personajes y situaciones inolvidables. Entre los primeros se cuentan el humanista Settembrini, el nihilista Naphta, la bella rusa Clawdia Chauchat, el estrambótico Peeperkorn, el genial Doctor Behrens; en las segundas: la lectura de un libro de anatomía que le hace preguntar sobre el significado de la vida; la peligrosa excursión (citada al principio del artículo) por los valles alpinos inhabitados, donde la naturaleza es una fuerza carente de compasión; la cena en la que los huéspedes del Bergoff se convierten en una manada carnavalesca al ritmo de una música de ópera.

Hans se convence poco a poco de que su enfermedad de ninguna manera es un accidente, o un infortunio gratuito e innecesario, sino es la vida que lo está despertando de su ordinario sueño burgués, mismo que le había hecho creer que un puesto de ingeniero naval en un importante astillero del mar del norte era lo máximo a lo que podía aspirar su existencia. El protagonista, gracias a la enfermedad, descubre la vida, cuyos ritmos son 
marcados ahora por la montaña más que por el frenesí sin forma de la ciudad moderna. En ese nuevo contexto, como se ha visto, incluso el cáncer se le muestra en toda su esplendorosa y amenazante belleza: una forma de la vida lujuriosa, depravada e indiferente, que busca otras soluciones, que avanza hacia la muerte, sí, pero siempre de una manera ocurrente. En consideración de su nueva situación, regresar a la vida ordinaria le parece un desacato. Él quiere permanecer en la montaña porque es el único lugar donde las voces del mundo llegan diáfanas a sus oídos y traducen los movimientos de su conciencia renovada. El joven entra en una nueva experiencia del tiempo, cuyas cadencias son ahora las del termómetro que mide su fiebre, de la tumbona en que descansa después de cada comida, de sus lecturas, de los largos paseos por la montaña, de las muchas charlas con sus nuevos compañeros de viaje (los otros enfermos), de los recuerdos pasados de su vida, del madurar de un amor inesperado por una misteriosa mujer asiática.

El lector, finalmente, se descubre en su viaje junto a Hans, y se da cuenta de que la novela es también la suya, que su experiencia del tiempo y de la enfermedad es de la misma índole que la de ese personaje, y que su vida también es una colección de objetos, situaciones y pensamientos, al mismo tiempo casuales y necesarios, cuyo final está escrito por la muerte. 


\section{BIBLIOGRAFÍA}

Alighieri, Dante (1988): La Divina Commedia, Milano, Hoepli.

Bajtín, Mijaíl (2005): Problemas de la poética de Dostoievski, Buenos Aires, Fondo de Cultura Económica.

Bajtín, Mijaíl (2003): La cultura popular en la Edad Media y el Renacimiento, Madrid, Alianza Editorial.

Bacarlett, María Luisa (2006): Friedrich Nietasche, la vida, el cuerpo y la enfermedad, Ciudad de México, UNAM.

Bateson Gregory, Bateson Mary Catherine (2013): El temor de los ángeles, Barcelona, Paidós.

Burger, Peter (1994): «La verdad estética», en Criterios, 31: 5-23.

Calvino, Italo (2016): Lezioni americane, Milano, Mondadori.

Camus, Albert (2012): La Caída, Madrid, Alianza Editorial.

Canetti, Elias (2013): Masa y poder, Madrid, Alianza Editorial.

Carr, David (1999): «Art, Practical Knowledge and Aesthetic Objectivity», en Ratio, 12: 240256.

Dewey, John (1934): Art as Experience, New York, Perigee Books.

De Maupassant, Guy (2008): La Horla, Ciudad de México, Gandhi Ediciones.

Dutton, Denis (2014): El instinto del arte, Barcelona, Paidós Ibérica.

Galilei, Galileo (2008): Dialogo sopra i due massimi sistemi del mondo, Bologna, BUR-Rizzoli.

Grmek, Mirko, Gourevitch, Danielle (2000): Le malattie nell'arte antica, Firenze, Giunti.

Janz, Curt Paul (1982): Vita di Nietzsche. Vol. III, Bari, Laterza.

Konrad, Joseph (2011): Corazón de las tinieblas, Xalapa, Universidad Veracruzana.

Mann, Thomas (2010): Doktor Faustus, Buenos Aires, Edhasa.

Mann, Thomas (2005): La montaña mágica, Buenos Aires, Edhasa.

Mann, Thomas (1982): La muerte en Venecia, Barcelona, Plaza \& Janes.

Menninghaus, Winfried (2015): A cosa serve l'arte? L'estetica dopo Darwin, Verona, Fiorini Editore.

Monod, Jacques (2007): El azar y la necesidad: ensayo sobre la filosofía natural de la biología moderna, Barcelona, Tusquets.

Morabito, Raffaele (2018): L'idea della scrittura tra medioevo e umanesimo, Roma, Carocci.

Nietzsche, Friedrich (2008): Así habló Zaratustra, Madrid, Alianza Editorial.

Nietzsche, Friedrich (2005): Ecce homo. Como se llega a ser lo que se es, Madrid, Alianza Editorial. 
Nietzsche, Friedrich (2002): La Gaya Ciencia, Madrid, EDAF.

Reyes, Alfonso (2012): Cuestiones estéticas, Monterrey, UANL.

Surdich, Luigi (2008): Boccaccio, Bologna, Il Mulino.

Svevo, Italo (2009): La conciencia de Zeno, Madrid, Debolsillo.

Tabucchi, Antonio (2013): Sostiene Pereira, Barcelona, Anagrama. 
SOBRE EL AUTOR

\section{Francesco Panico}

Postdoctorado en el Centro de Investigaciones en Geografía Ambiental (CIGA) de la Universidad Nacional Autónoma de México (UNAM). Doctor en Historia y Estudios

Regionales por la Universidad Veracruzana (Xalapa, México). Licenciado en Letras Modernas por la Università degli Studi di Perugia (Italia). Académico de Tiempo Completo "Titular C" de la Facultad de Ciencias Sociales de la Universidad Veracruzana. Sistema Nacional de Investigadores Nivel I.

Contact information: Universidad Veracruzana, Lomas del Estadio s/n CP 91000 Colonia Zona Universitaria, +522288421700, fpanico@uv.mx. 